\title{
Knowledge Hiding in Academia: Is Personality a Key Factor?
}

\author{
Nihan Demirkasımoğlu ${ }^{1}$ \\ ${ }^{1}$ Hacettepe University, Faculty of Education, Department of Educational Sciences, Beytepe, Ankara/Turkey \\ Correspondence: Nihan Demirkasımoğlu, Hacettepe University, Faculty of Education, Department of Educational \\ Sciences, Beytepe, Ankara/Turkey \\ Received: November 15, 2015 \\ Accepted: December 11, 2015 Online Published: December 15, 2015 \\ doi:10.5430/ijhe.v5n1p128 \\ URL: http://dx.doi.org/10.5430/ijhe.v5n1p128
}

\begin{abstract}
The purpose of this paper was to analyze the knowledge hiding types of academicians and their relationship between personality traits. It was designed as a quantitative study. Data was gathered from 386 research assistants and assistant professors from Turkish universities. Knowledge hiding scale developed by Connelly, Zweig, Webster and Trougakos (2012) was adapted to Turkish by the author and personality traits were assessed by the Turkish version (Karanc1, Dirik and Yorulmaz, 2007) of Eysenck's scale (Francis, Laurence, and Philipchalk, 1992). Results suggested that knowledge hiding behavior is not a prevalent phenomenon in academia. Academicians relatively highest knowledge hiding behaviors were related to "rationalized hiding" followed by "evasive hiding" and" playing dumb". Academicians "play dumb" to their superiors whereas they act "rationalized hiding" to co-workers. Extraversion was positively correlated with playing dumb while neuroticism had a negative correlation.
\end{abstract}

Keywords: Knowledge hiding, Personality traits, Academicians

\section{Introduction}

\subsection{Problem}

The interest to the concept of knowledge management in different organizational settings grew significantly during the 1990s. Knowledge sharing and knowledge transfer are one of the most widely researched topics of professional and academic discourse in different fields such as management, information sciences, sociology and economics. Although numerous authors discussed the knowledge sharing behaviors in organizations (e.g. Lee, So, and Tang, 2000; Lin, 2007; Lin and Lee, 2004; Srivastava, Bartol, and Locke, 2006; Tangaraja and Rasdi, 2013; Tohidinia and Mosakhani, 2010), few studies have attempted to investigate the knowledge hiding behaviors of employees (e.g. Connelly, Zweig, Webster and Trougakos, 2012; Peng, 2013; Cerne, Nerstad, Dysvik and Škerlavaj, 2013). A number of empirical studies concerning the knowledge management concept pointed out the shortcomings of "knowledge hiding" dimension with regard to different work settings (e.g. Greenberg, Brinsfield and Edwards, 2007; Webster, Brown, Zweig, Connelly, Brodt, and Sitkin, 2008; Connelly et al., 2012).

Despite an increasing attention to the knowledge sharing behaviors of employees in different workplace settings, little is known about the academicians' knowledge hiding behaviors in academia. As Mohayidin, Azirawani, Kamaruddin and Idawati (2007) stated, the primary concern of the universities is to develop quality graduates, with analytical and problem solving skills and interpersonal understanding as part of their learning achievements, thereby, contributing to the nation's goal of building a knowledge-based society. In short, sharing knowledge is the main reason of universities' existence (Kidwell, Vander Linde and Johnson, 2000).

Limited number of knowledge management studies in academia covers different themes. In a study by Nawi, Shukor, Basaruddin, Rahim, Hassan and Jusoff (2012), it was found that knowledge management processes consisted of "knowledge capturing, knowledge organizing, knowledge refining, and knowledge transferring" existed among academicians. A study about university students' knowledge transfer behaviors showed that competition had a stonger role in knowledge sharing while its role decreased in knowledge hiding behaviors (Connelly, Ford, Gallupe, Turel and Zweig, 2009). Hughes, Tapp, and Hughes (2008) investigated the nature of knowledge exchange between academics and practitioners in the marketing field. They found out that practitioners show considerable resistance to engage with academia by many individuals whereas academics are out of touch with reality. In another study by Muhenda and Lwanga (2014), researchers tested whether knowledge hoarding in higher education institution was considered as a strategy or a risk. Their findings did not display concrete evidences of knowledge hoarding. In the light of these references, it is possible to assert that knowledge hiding concept in academia is an underresearched 
subject.

Since academicians are one of the main generators and producers of knowledge, it is important to examine how they tend to behave when their co-workers and superiors request necessary or valuable information from them. This study is an attempt to provide a descriptive picture of which types of knowledge hiding behaviors academicians demonstrated and how frequent these behaviors took place. I assumed that knowledge hiding behaviors of academicians may vary towards co-workers and superiors based on the arguments of Servin and De Brun (2005) who indicated that employees generally prefer to learn from their peers than from managers. Furthermore, Husted and Michailova (2002) asserted that subordinates intentionally hoard knowledge at the thought that superiors dislike the subordinates who appear to be more knowledgeable than themselves. Considering these arguments, the measurement of knowledge hiding behaviors were both targeted to co-workers and superiors in empirical part of this research. To this end, this study illuminates the undesirable side of knowledge management in academia.

The main objective of this study was to document how knowledge hiding types of research assistants and assistant professors relate to personality traits in Turkish universities. Research assistants and assistant professors are selected because they both work with superiors and co-workers. Besides, their positions are open to antagonism, they may be familiar with the multiple aspects of this workplace phenomenon. As mentioned before, research findings proved that knowledge hiding behaviors take shape according to hierarchical positions (e.g. Husted, and Michailova, 2002). Within this frame, specifically the following research questions were addressed:

Which types of knowlege hiding behaviors do Turkish academicians display?

How frequent do the academicians display knowledge hiding behavior types?

Do academicians' knowledge hiding behaviors vary according to sex, academic title and field of study?

Is there a correlation between academicians' knowledge hiding types and personality traits?

A number of previous studies have reported correlations between personality traits and knowledge management behaviors (e.g. Matzler, Renzl, Müller, Herting and Mooradian, 2008; Mooradian, Renzl and Matzler, 2006; Wang and Yang, 2007). Since personality traits found to be related to knowledge sharing, the relationship between knowledge hiding and personality traits seemed to be worth researching. To author's knowledge, this study is the first to examine the relationship between the knowledge hiding types of academicians and their personality traits in terms of some variables.

\section{Conceptual Background}

\subsection{Knowledge Management}

In the information age, knowledge is considered as a key to competitiveness and it is broadly used to cover all that an organization needs to know to perform its functions. Knowledge includes formalized knowledge, patents, laws, programmes, procedures as well as the experience of people and the ways of doing business (Watson, 2003). Husted and Michailova (2002) reported that a study consisting more than 700 U.S companies proved that only a small portion of corporate knowledge is in a sharable form wheras the majority is retained in employee's minds. At this point, an organization's primary focus should be on developing a knowledge-friendly culture and knowledge-friendly behaviours among employees, which should be supported by the appropriate processes, and which may be enabled through technology (Servin and De Brun, 2005).

Knowledge management is the process of transforming information and intellectual assets into enduring value (Kidwell et al., 2000). Land, Nolas and Amjad (2005) proposed that knowledge management is related to a set of activities such as acqusition, creation, dissemination, storage, hiding, disposing, sharing and controlling the use of knowledge. In academia, knowledge management initiative intends to achieve specific outcomes such as improved performance through shared intelligence and higher levels of innovation (Mohayidin et al., 2007). One of the main tasks in knowledge management is to promote knowledge and take the possible steps to stop employees' knowledge hiding. In a study conducted in Malaysian universities, findings indicated that knowledge management practices were perceived as a work routine by the lecturers that will lead an improvement in the performance of delivering their core duties (Mohayidin et al., 2005).

Within the knowledge management frame, researchers recently have discussed about two distinct constructs, namely "knowledge sharing" and "knowledge hiding". While operationalization of these constructs, they were not considered to be the opposites of each other but rather two conceptually distinct constructs (Connelly et al., 2012; Ford and Staples, 2010). Although companies and organizations spend effort to create knowledge sharing settings, they fail to a great extent and knowledge hiding is still prevalent in work settings today (Peng, 2013; Babrock, 2004; 
Connelly et al., 2012). Morover, this happens sometimes intentionally (Cerne et al., 2014). Similiarly, Owell and Annansinghi (2012) reported that although knowledge sharing is accepted to be necessary for knowledge refinement, generation and individual recognition and it is often a neglected activity. In a recent research on Chinese knowledge workers, the percentage of knowledge hiding behavior was reported as 59\% (Peng, 2012).

In order to understand the knowledge hiding construct, the fundamental concepts of knowledge management such as "knowledge sharing", "knowledge witholding" and "knowledge hoarding" should not be ignored. Organizations have taken different views on knowledge sharing. Some, believed that sharing should not be encouraged as it has the danger of giving the secrets away while others saw a great potiential benefit in disseminating knowledge within an organization (Husted and Michailova, 2002). Knowledge sharing is defined as "the exchange of knowledge between and among individuals, and within and among teams, organizational units and organizations" (King, 2008, 493-494). Organizations would find no way of leveraging past experiences and expertise without knowledge sharing and would constantly reinvent themselves (Owell and Annansinghi, 2012). Thus, it is possible to consider the phenomenon of knowledge sharing as a factor facilitating the work related interaction among employees.

\subsection{Knowledge Hiding}

Within the purpose of this research, the fundamental structure of Connelly, Zweig, Webster and Trougakos (2012) was utilized to a great extent. They propose that "knowledge hiding", "knowledge hoarding" and "knowledge sharing" constructs are potantially related and knowledge hiding is a unique construct as a component of knowledge transfer phenomenon. The authors defined the knowledge hiding structure as "an intentional attempt by an individual to withhold or conceal knowledge that has been requested by another person". A similar concept called as knowledge hoarding is different from knowledge hiding in the sense that a person may be unable to share the knowledge by mistake or ignorance.

Some people presumably have a tendency to share knowledge just as some people have a tendency to be talkative. Other follow the "knowledge is power" dictum, probably learned in organizational settings; these people may hoard knowledge and be reluctant to share it (King, 2008, 493-494) which cause inefficiency and fragmentation of services (Konstantinou and Fincham, 2011). Knowledge transmitters hoard their knowledge due to a number of reasons. One of them is related to the potential loss of market value which is "hardly won" after spending long years in education and training. This leads workers a stong feeling of personal ownership of accumulated knowledge. The second reason underlies the costly process of knowledge sharing which brings an extra responsibility or a burden to the transmitters in additon to the routine tasks. Third reason is, fear of hosting "knowledge parasites" who has put less effort for her/his development. Fourth, avoidance of external assessment of the quality of their knowledge. Lastly, subordinates intentionally hoard knowledge with the thought that superiors do not like knowledgeable subordinates than themselves and they do not want to accept that they can learn from subordinates. Conversely, superiors may intentionally hoard knowledge from subordinates to maintain their power (Husted and Michailova, 2002).

There are a number of different reasons behind knowledge hiding behaviors. Some of them covers personal reasons such as prosociality and laziness (Connelly et al., 2012) whereas some are related to cultural factors as Servin and De Brun (2005) pointed out. The authors stated that in the western tradition most of the employees have been trained to believe in individual effort and compete for better working conditions such as promotions, status and salaries. They further explained some of the barriers of not sharing the knowledge as follows: "Knowledge is power", "employees do not have time", "that's not my job", "you're just using other people's ideas and taking the credit", "that's not how we do things around here", "I don't trust them", "don't bother others by asking them for help, work it out for yourself", "you should already know all the answers" and "it's just another management fad; if I ignore it, it'll eventually go away". Among these, "not having time" is one of the most common barriers he underlines because people are too busy with "real work". In addition to these, Peng (2013) questioned why and when employees hide knowledge. He found that individuals tend to hide knowledge when they have strong psychological ownership feelings over knowledge. Though knowledge hiding and knowledge hoarding are distinct constructs as mentioned before, the factors behind these contructs seem quite similiar.

Some authors referred to the knowledge hiding issue by the "knowledge withholding" term. For example, Lin and Wang (2012) define knowledge witholding as concealing the knowledge that is important or valuable to others. Duffy, Ganster and Pagon (2002) addressed the issue of knowledge witholding as a form of social undermining at work. According to the authors, an employer may engage in active or passive verbal undermining behaviors, by witholding the needed knowledge, making belittling comments to a target as well as "silent treatment". Thus, as Connelly et al. (2012) stated knowledge hiding behaviors include "intentional" and "active" attempts, but not includes "the behaviors of failing to share by mistake, accident, or ignorance". 
Knowledge hiding takes different forms and results in different organizational behavior among employees (Connelly and Kelloway, 2003). Despite being a relatively low-base-rate event, knowledge hiding behavior causes a series of problems destroying organizational creativity, innovation, and performance. An employee requesting knowledge from a colleague responds in the same way when knowledge is withheld intentionally. Cerne et al., (2014) defines this situation with "shooting yourself in the foot" which means that selfish treatment in turn finds the knowledge keeper. It signifies that interpersonal relationships may be destroyed by mutual distrust. Peng (2013) also suggested that knowledge hiding in an organization may harm organizational performance by damaging the collaborations, development of new ideas, or the implementations of policies. Drawing on social exchange theory, in a field study of 240 employees, researchers proved that knowledge hiding behavior was found to be a negative factor on employees' creativity (Cerne et al., 2014). On the other side, there are situations when telling the truth to everyone is not the best solution (Takala and Urpilainen, 1999). Thus, knowledge hiding is not considered to be a fully negative phenomenon when knowledge hiders intend to protect themselves, a colleague or the other party's feelings and it can take different forms. One of them is evasive hiding that involves some deception in which case, knowledge hider presents false or misleading information. Second type is playing dumb that knowledge hider acts as if s/he is ignorant of the requested knowledge. This dimension also involves some deception like evasive hiding. Third type is rationalized hiding that knowledge hider presents a justification for not sharing the knowledge, sometimes blaming another party (Connelly et al.,2012). In short, knowledge hiding in organizations is a well-known phenomenon and employees use different strategies to hide their knowledge. The main question within the boundaries of the study is, in what ways academicians hide knowledge from their collegues and how frequent this action takes place.

\subsection{Eysenck's Personality Theory}

Since 1950s, scholars attempted to present a special version of trait theory as an acceptable descriptive paradigm called Big-Five, based on the lexical hypothesis (Eysenck, 1997). There is a widespread acceptance that personality traits are organized hierarchically. In such a representation, the Big-Five domains present a scientific framework which characterizes human behavior including and systemizing multitudinous individual differences rather than reducing it to mere five traits. Even now, there is not a universal agreement on this five factor model. For example, while Catell believes that there are more factors than five, Eysenck is sure that five is too many (Goldberg, 1993). Eysenck (1992) asserted that a reasonable case of three-factor model considering all of the existing factorial studies of personality can be made instead of five-factor model based on the existing evidence he provided.

Based on a series of well supported sets of assumptions, Eysenck and Eysenck (1985) developed a hierarchical approach to personality, namely Revised Eysenck Personality Questionnaire (EPQR). The trait model formulated by Eysenck defines the three supertraits Extraversion, Neuroticism and Psychoticism. Extraversion refers to "outgoing, uninhibited, impulsive and sociable inclinations of a person". Extraverts have many social contracts and often take part in group activities. They like having friends and talking to them and do not like reading or studying themselves. They are characterized to be carefree, easygoing, optimistic, cheerful and their feelings are not kept under tight control. Neuroticism refers to "the general emotional overresponsiveness and liability to neurotic breakdown under stress" and this dimension is related to emotional lability and overreactivity. Neurotics are identified by emotionally overresponsive and they have difficulties in handling emotional experiences. They are more likely to complain about negative effects of stress, anxiety and dissappoinments (Eyscenk and Eyscenk, 1968). The third dimension "psyhoticism" is related to lack of sensitivity and disregard for social conventions. The essential components of this dimension appear to be tendency to deviant behaviors (Fulker, 1981; Levey and Martin, 1981, 110-166).

Eysenck developed several scales to measure the personality traits (e.g. Eysenck, 1952; Eysenck and Eysenck, 1964; Eysenck and Eysenck, 1975). More recently Francis, Laurence, and Philipchalk (1992) developed an abbreviated form of Eysenck, Eysenck and Barrett's (1985) EPQR, an instrument measuring Extraversion, Neuroticism, Psychoticisim and the Lie Scale. In EPQR, each scale contained 12 items for the four indices. Since long tests have some practical disadvantages, Francis, Brown and Philipchalk (1992), devised this scale in total of 24-item form in line with the same indices in which each indice contained six items.

\section{Method}

\subsection{Study Group Characteristics}

The study group was consisted of 386 academicians from Turkish universities from 12 regions of Turkey according to the Nomenclature of Units for Territorial Statistics classification used by European Union member states. Approxiamately 1000 surveys were mailed to the research assistants and assistant professors from colleges of education and engineering in each region during 2013-2014 academic year. The reason for selecting education and engineering colleges was because they could represent the different disciplines such as social and natural sciences. 
Participants gender percentages were almost same for female $(51 \%)$ and males $(49 \%)$ were male. $118(53 \%)$ of the participants were from colleges of education representing the social sciences field and $205(47 \%)$ of them were from colleges of engineering representing the natural sciences. The age of participants varied from 20 to 44 . The composition of the sample of academic titles is as follows: 207 (\%54) research assistants and 179 (\%46) assistant professors working in full time position. In Turkey, research assistants work in full time position as academic staff besides their graduate education.

\subsection{Measures}

\subsubsection{Knowledge Hiding Scale}

Knowledge hiding behaviors of academicians were measured with a five-point Likert scale ranging from "not at all" to "to a great extent" adapted from Connelly et al. (2012). Their scale was seven-point Likert scale consists of 21 items that define evasive hiding, lack of sharing, and playing dumb, rationalized hiding, and knowledge hoarding. Connelly and his friends performed an explanatory factor analysis based on the 194 employees from a voluntary online panel of English-speaking adults. They found that five factors formed the twenty-one items including both knowledge hiding and knowledge sharing behaviors.

Within the purpose of this study, "sharing" and "knowledge hoaring" sub-scales were excluded since they do not directly related to knowledge hiding behaviors. In order to discover the knowledge hiding behaviors of academicians through self-report, twelve-item scale consisting of "evasive hiding", "playing dumb" and "rationalized hiding" dimensions was adopted into Turkish. KHS was measured by a 5-item scale ranging from 1 (never) to 5 (always). This form of the scale includes items such as: "I agreed to help him/her but never really intend to (evasive hiding), "I pretend that I do not know the information (playing dumb)", and "I explain that I would like to tell him/her, but is not supposed to (rationalized hiding)". In order to test the validity of the scale, items were translated into Turkish by the author and then reviewed by two bilingual experts in the field of educational administration to assess the appropriateness and adequacy of the translation. Feedbacks from experts were reviewed independently and an appropriate form was achieved based on consensus. In this research, the scale items were designed as two-sided, each item was adressed to both superiors and co-workers. In other words, the respondents were asked to rate each item for their "co-workers" and "superiors". By differing these positions, the researcher wished to see whether the knowledge hiding behavior was effected from the positions hold in the organization. Confirmatory factor analyses were conducted to determine the factorial validity of the scales using LISREL 8.54. Using the maximum likelihood estimation, the fit indices of measurement model was estimated (Figure 1).

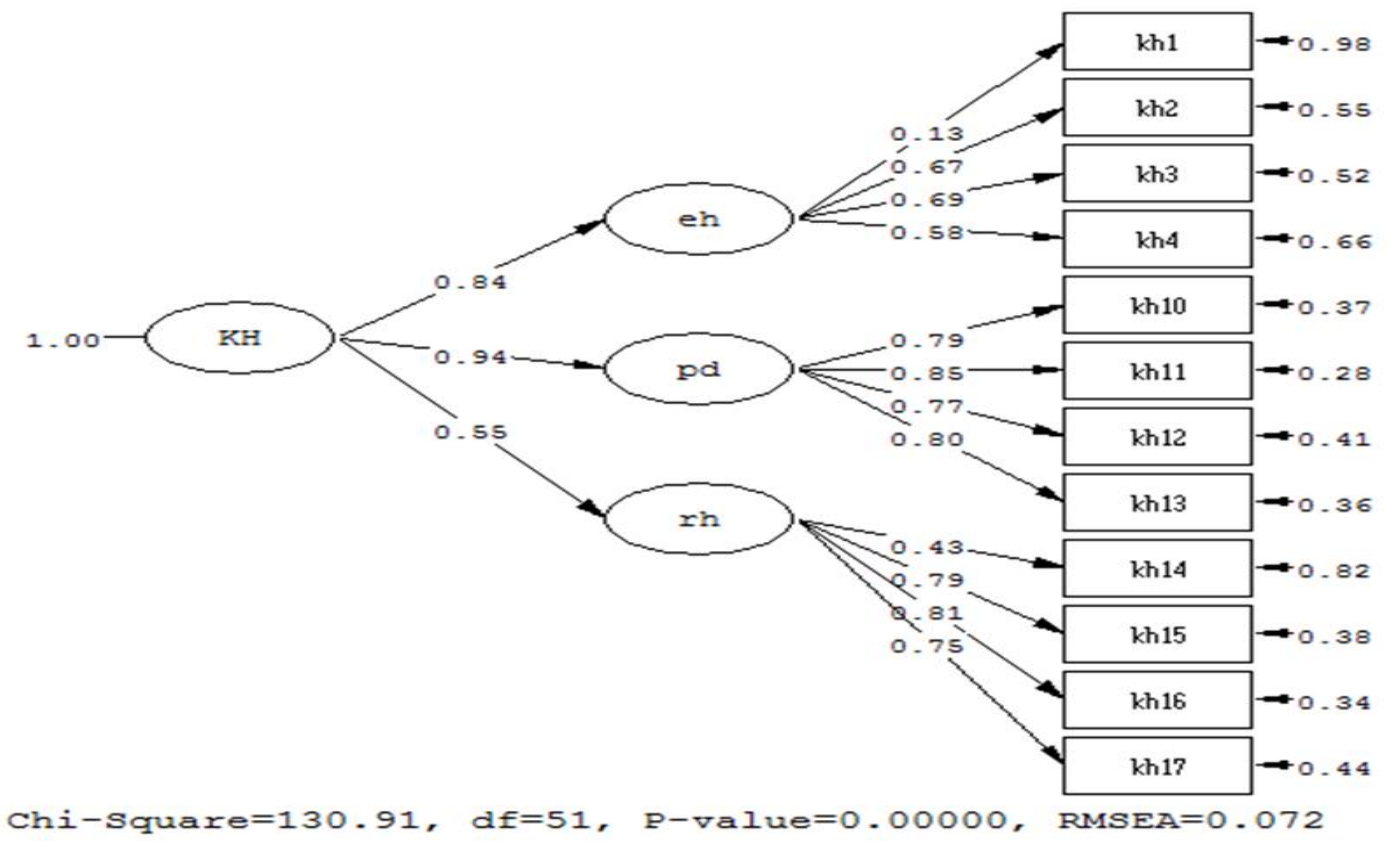

Figure 1. Path Diagram of Knowledge Hiding Scale 
The CFA results showed that the hypothesized three-factor model (evasive hiding. playing dumb and rationalized hiding) confirmed the original version of the scale and fits the data well (GFI $=.93$. AGFI $=.90 . \quad \mathrm{CFI}=.97$. NFI $=.95 . \mathrm{NNFI}=.96 . \mathrm{RMSEA}=.07)$. A non-significant chi-square value represented the fitness of the model $\left(\chi^{2 / \mathrm{df}=}\right.$ 2.56). Good internal consistency was found (Cronbach's alpha=.77). All item total correlations were greater than 0.40 . Both these results indicated that the KHS has good reliability.

\subsubsection{Personality Scale}

Personality traits of academicians was assesed using the Turkish adaptation of the "Eysenck Personality Questionnaire Revised-Abbreviated Form (EPQR-A) (Francis et al., 1992)" by Karanc1, Dirik ve Yorulmaz (2007). This 24-item measure was designed to assess personality regarding neuroticism, extraversion, psychoticism, and lying with six items each sub-scale. Participants expected to reply each item as "yes (1 point)" or "no (0 point)" so, each sub-scale scores range from zero to six. This instrument included items such as, "are you a talkative person? (extraversion dimension)", "does your mood often go up and down? (neuroticism dimension)", "would being in debt worry you? (psychoticism dimension)", and "have you ever cheated at a game? "(lying dimension)".

Factor analysis results reported by Karanc1 et al. (2007) were similar to the original scale and yielded four factors consistent with the original scale. Kuder-Richardson Alpha coefficients for the extraversion, neuroticism, psychoticism, and lie scales were $0.78,0.65,0.42$, and 0.64 respectively. The test-retest reliability of the scales was $0.84,0.82,0.69$, and 0.69 respectively. Although factor analyses conducted by Karanc1 et al. (2007) supported the construct validity and reliability of the original scale of Francis et al. (1992), the internal consistency needs to be tested within for the academicians since their sample consisted of university students. Cronbach's alphas for each subscale were $.83,60, .73$, and .51 respectively for the academician group. The alpha coefficient obtained herein for the psychoticism dimension performed poorly (.51) consistent with the previous difficulties in measuring this sub-scale in other cultures (e.g. Tiwari, Singh ve Singh, 2009; Francis et al., 1992; Francis et al., 2006). Yet, psychoticism subscale was applied in the current study to keep the unity of the scale and to compare the relationship of this variable with other researches.

\section{Results and Discussion}

\subsection{Findings Related to Knowledge Hiding Behaviors of Academicians}

Regarding the nature of knowledge hiding behavior, the pattern of mean response to knowledge hiding items was examined. Descriptive statistics of knowledge hiding behaviors of academicians can be seen in Table 1 . 
Table 1. Descriptive statistics of knowledge hiding behaviors

\begin{tabular}{|c|c|c|c|c|c|}
\hline & \multirow[b]{2}{*}{ Items } & \multicolumn{2}{|c|}{ Co-workers } & \multicolumn{2}{|c|}{ Superiors } \\
\hline & & $\mathrm{M}$ & SD & M & SD \\
\hline \multirow{5}{*}{ 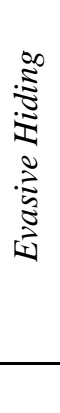 } & I agree to help him/her but never really intend to. & 3.37 & 1.17 & 3.28 & 1.23 \\
\hline & $\begin{array}{l}\text { I agree to help him/her but instead give him/her information } \\
\text { different from what s/he wanted. }\end{array}$ & 1.05 & .25 & 1.12 & .39 \\
\hline & $\begin{array}{l}\text { I tell him/her that I would help him/her out later but stall as much } \\
\text { as possible }\end{array}$ & 1.21 & .44 & 1.26 & .53 \\
\hline & $\begin{array}{l}\text { I offer him/her some other information instead of what he/she } \\
\text { really wants }\end{array}$ & 1.19 & .47 & 1.15 & .42 \\
\hline & Total & 1.70 & .37 & 1.70 & .42 \\
\hline \multirow{5}{*}{ 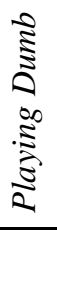 } & I pretend that I do not know the information & 1.26 & .53 & 1.38 & .67 \\
\hline & I say that I do not know. even though I do & 1.14 & .41 & 1.25 & .56 \\
\hline & I pretend I do not know what s/he was talking about & 1.58 & .75 & 1.48 & .73 \\
\hline & I say that I am not very knowledgeable about the topic & 1.17 & .44 & 1.25 & .57 \\
\hline & Total & 1.28 & .42 & 1.33 & .53 \\
\hline \multirow{5}{*}{ 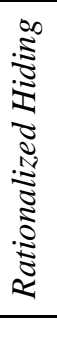 } & I explain that I would like to tell him/her but was not supposed to & 2.29 & 1.24 & 2.02 & 1.12 \\
\hline & $\begin{array}{l}\text { I explain that the information is confidential and only available to } \\
\text { people on a particular project }\end{array}$ & 1.53 & .80 & 1.42 & .74 \\
\hline & $\begin{array}{l}\text { I tell him/her that my boss would not let anyone share this } \\
\text { knowledge }\end{array}$ & 1.42 & .72 & 1.38 & .68 \\
\hline & I say that I would not answer his/her questions & 1.43 & .71 & 1.32 & .65 \\
\hline & Total & 1.66 & .60 & 1.53 & .58 \\
\hline
\end{tabular}

As seen in Table 1, among the knowledge hiding behaviors, "evasive hiding" received relatively the highest ratings and followed by the "rationalized hiding" and "playing dumb". The most frequent knowledge hiding behaviors of academicians towards both their co-workers and superiors were "I agree to help him/her even if I really do not intend to" ( $\mathrm{M}=3.37$; 3.28) (for evasive hiding), "I explain that I would like to tell him/her but was not supposed to" $(\mathrm{M}=2.29 ; 2.02)$ (for rationalized hiding) and "I pretend I do not know what $\mathrm{s} /$ he was talking about" $(\mathrm{M}=1.58 ; 1.48)$ (for playing dumb). On the other hand, academicians mean scores related to knowledge hiding dimensions ranged between 1.28 (the lowest) and 1.70 (the highest) which pointed that these behaviors occured very rarely. Therefore, knowledge hiding was not a widespread phenomenon among the academicians included in this study.

A paired-samples t-test was conducted to compare whether the knowledge hiding behaviors of academicians towards their co-workers and superiors were different. There was a significant difference in the scores of academicians playing dumb to "co-workers" $(\mathrm{M}=5.15, \mathrm{SD}=1.68)$ and to "superiors" $(\mathrm{M}=7.37, \mathrm{SD}=2.77), \mathrm{t}(385)=20.246, \mathrm{p}<.001$. The t-test results also indicated that there was a statistically significant difference in the scores for rationalized hiding to "co-workers" $(\mathrm{M}=6.67, \mathrm{SD}=2.43)$ and to "superiors" $(\mathrm{M}=6.13 ; \mathrm{SD}=2.35), \mathrm{t}(385)=5.97, \mathrm{p}<.001$. This means that academicians were more likely to "play dumb" to their superiors than to co-workers when they were hiding knowledge. This finding is in line with the assertion of Husted and Michailova (2002) that superiors do not like more knowledgeable academicians than themselves. This may be a way of self-protection adopted by academicians. In a study by Kasimoglu and Halici (2002), it was found that successful and hard working workers were facing continuous pressure. In line with this finding, there is a prevelant opinion that if an employee does his duty well, s/he is punished with more work. Shortly, when academicians play dumb, they will be thinking it as a way of protecting themselves from over workload and pressure. The second point revealed out with these findings is that, academicians more act "rationalized hiding behaviors" to their co-workers than to their superiors. There can be practical reasons behind this situation. Employees may be feeling themselves more comfortable with the co-workers and they may be presenting rational reasons. Also, they may be finding more easy to act as if they do not know while communicating 
with the superiors. In summary, academicians' knowledge hiding types may be depending on the organizational communication patterns that are dominant in academia.

4.2 Academicians' Knowledge Hiding Behaviors according to Gender, Academic Title and Academic Discipline Variables

\subsubsection{Gender}

There is a statistically significant mean difference in evasive hiding behaviors of academicians towards their co-workers between males and females $(\mathrm{t}(384)=2.23, \mathrm{p}<.005)$ as shown in Table 2 . It means that female academicians are more likely display evasive knowledge hiding behaviors.

Table 2. Results of t-test and Descriptive Statistics for Knowledge Hiding by Gender

\begin{tabular}{lllllllll}
\hline & \multicolumn{2}{c}{ Male } & \multicolumn{2}{c}{ Female } & \multirow{2}{*}{$\mathrm{d}$} & $\mathrm{df}$ & $\mathrm{p}$ \\
\cline { 1 - 7 } & $\mathrm{M}$ & $\mathrm{SD}$ & $\mathrm{M}$ & $\mathrm{SD}$ & & & \\
\hline Evasive Hiding (co-workers) & 6.66 & 1.41 & 7.00 & 1.59 & 2.23 & 384 & .02 \\
\hline Evasive Hiding (superiors) & 6.78 & 1.62 & 6.83 & 1.76 & .286 & 384 & .24 \\
\hline Playing dumb (co-workers) & 5.05 & 1.71 & 5.26 & 1.64 & 1.17 & 384 & .24 \\
\hline Playing dumb (superiors) & 7.06 & 2.62 & 7.71 & 2.89 & 2.30 & 384 & .77 \\
\hline Rationalized Hiding (co-workers) & 6.62 & 2.41 & 6.72 & 2.45 & .399 & 384 & .69 \\
\hline Rationalized Hiding (superiors) & 5.97 & 2.24 & 6.32 & 2.46 & 1.44 & 384 & .15 \\
\hline
\end{tabular}

$* \mathrm{p}<.05$.

As can be seen from Table 2, female and male academicians did not significantly differ in their knowledge hiding types in playing dumb and rationalized hiding types ( $p>.05)$.

\subsubsection{Academic Title}

There is a statistically significant mean difference in knowledge hiding behaviors of academicians towards their co-workers and superior as shown in Table 3.

Table 3. Results of t-test and Descriptive Statistics for Knowledge Hiding by Academic Title

\begin{tabular}{llllllll}
\hline \multicolumn{7}{c}{ Research Assistant } & \multicolumn{2}{l}{ Assistant Professor } & & \\
\hline & $\mathrm{M}$ & $\mathrm{SD}$ & $\mathrm{M}$ & $\mathrm{SD}$ & $\mathrm{t}$ & $\mathrm{df}$ & $\mathrm{p}$ \\
\hline Evasive Hiding (co-workers) & 6.90 & 1.54 & 6.73 & 1.46 & 1.14 & 384 & .25 \\
\hline Evasive Hiding (superiors) & 7.09 & 1.73 & 6.47 & 1.57 & 3.62 & 384 & .00 \\
\hline Playing dumb (co-workers) & 5.32 & 1.77 & 4.95 & 1.55 & 2.18 & 384 & .03 \\
\hline Playing dumb (superiors) & 7.71 & 2.79 & 6.98 & 2.70 & 2.58 & 384 & .01 \\
\hline Rationalized Hiding (co-workers) & 6.89 & 2.47 & 6.40 & 2.36 & 1.98 & 384 & .04 \\
\hline Rationalized Hiding (superiors) & 6.33 & 2.45 & 5.91 & 2.21 & 1.74 & 384 & .08 \\
\hline
\end{tabular}

Research assistants $(\mathrm{M}=7.09, \mathrm{SD}=1.73)$ and assistant professors $(\mathrm{M}=6.47, \mathrm{SD}=1.57)$ demonstrated a significant difference in "evasive hiding" behaviors towards their superiors. This means that research assistants provide misleading and incorrect knowledge to their superiors than assistant professors do. There is a significant difference about intentional falsification towards the superiors between the behhaviors of research assistants and assistant professors. Secondly, research assistants reported significantly higher levels of "playing dumb" to co-workers $(\mathrm{M}=$ $5.32, \mathrm{SD}=1.77)$ and superiors $(\mathrm{M}=7.72, \mathrm{SD}=2.79)$ than assistant professors. In other words, playing dumb is a knowledge hiding strategy that research assistants apply more than assistant professors. Research assistants $(\mathrm{M}=$ $6.89, \mathrm{SD}=2.47$ ) also significantly differ from assistant professors in terms of rationalized hiding behaviors towards co-workers which means that they provide a justification for failing to share the requested information more than assistant professors. To sum up, knowledge hiding behavior types especially towards the superiors were more applied by research assistants than the assistant professors. 


\subsubsection{Academic Discipline}

Academicians' knowledge hiding types related to academic discipline variable is presented in Table 4 .

Table 4. Results of t-test and Descriptive Statistics for Knowledge Hiding by Academic Discipline

\begin{tabular}{llllllll}
\hline & \multicolumn{2}{l}{ Social Sciences } & Natural Sciences & & \\
\hline & $\mathrm{M}$ & $\mathrm{SD}$ & $\mathrm{M}$ & $\mathrm{SD}$ & $\mathrm{t}$ & $\mathrm{df}$ & $\mathrm{p}$ \\
\hline Evasive Hiding (co-workers) & 6.72 & 1.48 & 6.89 & 1.52 & 1.19 & 381 & .26 \\
\hline Evasive Hiding (superiors) & 6.74 & 1.73 & 6.86 & 1.64 & .73 & 381 & .46 \\
\hline Playing Dumb (co-workers) & 5.17 & 1.82 & 5.12 & 1.54 & .30 & 381 & .75 \\
\hline Playing Dumb (superiors) & 7.36 & 2.72 & 7.37 & 2.82 & .20 & 381 & .98 \\
\hline Rationalized Hiding (co-workers) & 6.58 & 2.35 & 6.73 & 2.50 & .61 & 381 & .54 \\
\hline Rationalized Hiding (superiors) & 6.06 & 2.18 & 6.20 & 2.49 & .59 & 381 & .55 \\
\hline
\end{tabular}

As can be understood from Table 4, knowledge hiding behaviors of academicians did not significantly differ between academicians from social and natural sciences ( $>>.05)$.

\subsection{Relationships between Knowledge Hiding Behaviors and Personality Traits of Academicians}

Of the personality variables, extraversion and neuroticism had a significant correlation with knowledge hiding behaviors. The bivariate correlations between knowledge hiding behaviors of academicians and personality traits showed that extraversion, neuroticism and psychoticism were significantly correlated with evasive hiding, playing dumb and rationalized hiding behaviors of academicians (Table 5).

Table 5. Pearson Correlations Between Knowledge Hiding Behaviors and Personality Traits

\begin{tabular}{|c|c|c|c|c|c|c|c|c|c|c|c|}
\hline Variable & $\mathrm{M}$ & SD & 1 & 2 & 3 & 4 & 5 & 6 & 7 & 8 & 9 \\
\hline $\begin{array}{ll}1 & \text { Evasive } \\
& \text { Hiding } \\
& \text { (co-workers) }\end{array}$ & 6.82 & 1.50 & 1 & & & & & & & & \\
\hline $\begin{array}{ll}2 & \text { Evasive } \\
& \text { Hiding } \\
& \text { (superiors) } \\
\end{array}$ & 6.80 & 1.69 & $.610 * *$ & 1 & & & & & & & \\
\hline $\begin{array}{ll}3 & \text { Playing } \\
& \text { Dumb } \\
& \text { (co-workers) } \\
\end{array}$ & 5.15 & 1.68 & $.315^{* *}$ & $.276^{* *}$ & 1 & & & & & & \\
\hline $\begin{array}{ll} & \text { Playing } \\
& \text { Dumb } \\
& \text { (superiors) }\end{array}$ & 7.37 & 2.77 & $.220 * *$ & $.378 * *$ & $.643 * *$ & 1 & & & & & \\
\hline $\begin{array}{ll}5 & \text { Rationalized } \\
& \text { Hiding } \\
& \text { (co-workers) } \\
\end{array}$ & 6.67 & 2.43 & $.208 * *$ & $.158 * *$ & $.410 * *$ & $.453 * *$ & 1 & & & & \\
\hline $\begin{array}{ll}6 & \text { Rationalized } \\
& \text { Hiding } \\
& \text { (superiors) } \\
\end{array}$ & 6.13 & 2.35 & $.158 * *$ & $.243 * *$ & $.397 * *$ & $.613 * *$ & $.734 * *$ & 1 & & & \\
\hline $7 \quad$ Extraversion & 2.39 & 2.11 & .066 & .074 & $.127 *$ & $.139 * *$ & .020 & .056 & 1 & & \\
\hline 8 Neuroticism & 3.57 & 1.90 & -.083 & -.094 & $-.106^{*}$ & $-.160 * *$ & -.058 & -.099 & $-.244 * *$ & 1 & \\
\hline 9 Psychoticism & 4.63 & 1.09 & .001 & -.059 & -.031 & -.026 & -.026 & .007 & $.123 *$ & .046 & 1 \\
\hline
\end{tabular}

* Correlation is significant at the 0.05 level (2-tailed).

As seen in Table 5, extraversion was significantly positively correlated with academicians' playing dumb behaviors towards both their co-workers $(\mathrm{r}=.12, \mathrm{p}<.05)$ and superiors $(\mathrm{r}=.13, \mathrm{p}<.01)$. In other words, extraverts play dumb more than the neurotics and psychotics. This significant relationship does not seem surprising because extraverts are sociable people who have good relationships. Extraverts may be playing dumb as a way of keeping their relationships good. That is, in this form of knowledge hiding, the keeper does not say "no" any way. It is quite simple 
and may be it seems more innocent and pretty than the other types of hiding from the knowledge requester's perspective. Neuroticism had a significant negative correlation with playing dumb towards co-workers $(r=.09 ; \mathrm{p}$ $=.05)$ and superiors $(\mathrm{r}=.10, \mathrm{p}=.01)$. This finding is consistent with the recent findings of Xenoudaki and Stafyla (2012). The authors have investigated the effect of situational factors and personal traits in the context of knowledge hiding. They found that playing dumb was negatively correlated with neuroticism just as the current research findings suggested. Moreover, these authors reported that rationalized hiding was not found to be correlated with any of the personality traits which is in the same line with the current research. Finally, psychoticism was not significantly related to any type of knowledge hiding perceptions $(\mathrm{r}=.00 ; \mathrm{r}=.05 ; \mathrm{r}=.03)$.

\section{Conclusions, Limitations and Implications}

While many knowledge hiding cases were reported in the literature, it seems not the case in Turkish academia. Based on the results of this survey, it was concluded that knowledge hiding was not a prevalent phenomenon. The reason for the low ratings of academicians may be resulted from a few factors. One reason may be the questionnaire utilized was based on the self-reports of academicians. Connelly et al. (2012) asserted that knowledge hiding may be a relatively underreported, low-base-rate event since knowledge hiding covers undesired behaviors in a workplace setting. Academicians might have tended to rate this event lower than the usual situation because of social desirability tendencies. Another reason may be that knowledge hiding responses may be reflecting the current picture of academicians' tendencies which is consistent with the findings of Muhenda and Lwanga (2014). The researchers reported that their findings did not provide concrete evidence of knowledge hoarding in higher educational institutions of Uganda. Knowledge hiding tendencies of academicians will be lesser than the other sector employees due to the nature of their work field which knowledge producing and disseminating is the reason of their existence. Additionally, as Durham and Burt (2009) argued, Eastern cultural norms may have some advantages in knowledge sharing intitiatives in organizations. Thus, these results may be suggesting that people from Turkey as representing the collectivist culture do not tend to knowledge hiding behaviors widely. Yet, the current study cannot address the main underlying factors of this rare occasion but future attempts should address this issue.

Despite being a rare phenomenon, at the times knowledge hiding occurred, evasive hiding tactics were the most rated while playing dumb was the least rated by academicians. This finding indicated that the type of academicians' knowledge hiding behaviors include misleading and falsification when colleagues require a necessary information for them. This finding is thought-provoking in the sense that this is a challenge in terms of academicians' roles and responsibilities. Besides, knowledge hiding types depends on the targets. If knowledge requirement comes from a co-worker, academicians provide rationalized hiding tactics while it comes from a superior, they tend to play dumb. Thus, hierarchical position, namely subordinate-superordinate relationships is a significant factor seems to shape the academicans behaviors. These findings may be suggesting that knowledge hiding tactics of academicians may have a common ground and they may be influenced by the organizational factors such as hiearachy, power and authority. Knowledge hiding behaviors did not significantly vary in relation to gender and academic discipline variables. On the other hand, generally research assistants tend to use knowledge hiding strategies than assistant professors. As expected, personality traits are related to knowledge hiding types. Extraverts more likely play dumb than neurotics and psychotics. In a way, this finding had an internal consistency within this study in the sense that there is negative correlation between playing dumb and neuroticism. Since neurotics are characterized by having trouble in controlling urges and responding more poorly to stressors, they may be less applying the playing dumb strategy than the extraverts and pychotics. Lastly, pyschoticisim is not a key factor for academicians' knowledge hiding mechanisms.

This study contributes to the literature on knowledge hiding by using data that employs a national sampling frame. So, this paper is the first to show that personal traits of academicians are associated with knowledge hiding types of academicians. Second, the present study builds on the stream of knowledge hiding phenomenon in organizations by examining it in a different setting. Another contribution of this research stems from the testing of its validity and reliability of Connelly, Zweig, Webster and Trougakos's (2012) knowledge hiding construct in Turkish context. This knowledge hiding construct provided an acceptable contruct in a Turkish organizational setting.

This study has some limitations. First, as it portrays a descriptive picture of academicians' knowledge hiding types, it only enlightens the dimension that which types of knowledge hiding behaviors are demonstrated and how frequent they are. Thus, the underlying reasons of their tendencies have not been scrutinized. In further studies, it will be enlightening to analyse these behaviours in dynamics. Second, within this study assistant professors and research assistants were included. An inclusive study covering other academic titles such as associate professors and full professors will provide valuable findings. Third, it should be noted that this study was carried out in a collectivist culture which cannot provide a generalization ground for the member of academic world. So, the comparative studies 
may provide different results or allow to make generalizations. Because this study employs self-reported scales for analyzing the knowledge hiding concept, future studies should apply other methods to overcome the possibility of under-reporting.

\section{References}

Babcock, P. (2004). Shedding light on knowledge management. fHR magazine, 49(5), 46-51.

Cerne, M., Nerstad, C., Dysvik, A. \& Škerlavaj, M. (2013). What goes around comes around: Knowledge hiding, perceived motivational climate, and creativity. Academy of Management Journal, 57 (1), 172-192. http://dx.doi.org/10.5465/amj.2012.0122

Connelly, C. E. \& Kelloway, E. K. (2003). Predictors of employees' perceptions of knowledge sharing cultures.

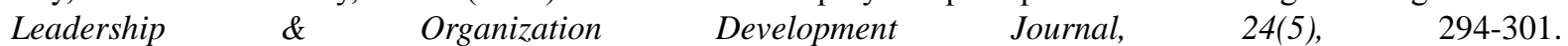
http://dx.doi.org/10.1108/01437730310485815

Connelly, C. E., Ford, D. P., Gallupe, B., Turel, O.\& Zweig, D. (2009). "The effects of competition and time constraints on knowledge transfer: Exploratory findings from two experiments" in System Sciences, in Hawaii International Conference, IEEE, 1-10.

Connelly, C. E., Zweig, D., Webster, J. \&Trougakos, J. P. (2012). Knowledge hiding in Organizations. Journal of Organizational Behavior, 33 (1), 64-88. http://dx.doi.org/10.1002/job.737

Duffy, M. K., Ganster, D. C. \& Pagon, M. (2002). Social undermining in the workplace, Academy of management Journal, 45 (2), 331-351. http://dx.doi.org/10.2307/3069350

Eysenck H. J. (1952). The Scientific Study of Personality. Routledge \&Kegan Paul, London.

Eysenck, H. J. \& Eysenck, M. W. (1985). Personality and Individual Differences: a natural science approach. New York: Plenum Press. http://dx.doi.org/10.1007/978-1-4613-2413-3

Eysenck, H. J. (1968). Manual for the Eysenck Personality Inventory. Educational and Industrial Testing Service, San Diego, CA.

Eysenck, H. J. (1992). Four ways five factors are not basic. Personality and Individual Differences, 13, 667-673. http://dx.doi.org/10.1016/0191-8869(92)90237-J

Eysenck, H. J. (1997). Personality and Experimental Psychology: The Unification of Psychology and the Possibility of a Paradigm, Journal of Personality and Social Psychology, 73 (6), 1224-1237. http://dx.doi.org/10.1037/0022-3514.73.6.1224

Eysenck, S. B. G., Eysenck, H. J. \& Barrett, P. (1985). A revised version of the psychoticism scale, Personality and Individual Differences, 6, 21-29. http://dx.doi.org/10.1016/0191-8869(85)90026-1

Francis, L. J., Brown, L. B. \& Philipchalk, R. (1992). The development of an abbreviated form of the Revised Eysenck Personality Questionnaire (EPQR-A): Its use among students in England, Canada, the USA and $\begin{array}{lllll}\text { Australia. Personality and } & \text { Individual }\end{array}$ http://dx.doi.org/10.1016/0191-8869(92)90073-X

Francis, L.J., Brown, L. B. \& Philipchalk, R. (1992). The development of an abbreviated form of the Revised Eysenck Personality Questionnaire (EPQR-A): its use among students in England, Canada, the USA and $\begin{array}{llllll}\text { Australia. Personality and Individual Differences, } 13 & \text { (4), } & \text { 443-449. }\end{array}$ http://dx.doi.org/10.1016/0191-8869(92)90073-X

Francis. L. J., Lewis. C. A. \& Ziebertz. H. G. (2006). The short-form revised Eysenck personality Questionnaire (EPQ-S): A German edition. Social Behavior and Personality, 34 (2), 197-204. http://dx.doi.org/10.2224/sbp.2006.34.2.197

Fulker, D. W. (1981). The genetic and environmental architecture of psychoticism, extraversion and neuroticism. In Eysenck, H. J. (Ed.), The structure and measurement of intelligence, Springer, New York, 102-132. http://dx.doi.org/10.1007/978-3-642-67783-0_4

Goldberg, L. R. (1993). The Structure of Phenotypic Personality Traits, American Psychologist, 48 (1), 26-34. http://dx.doi.org/10.1037/0003-066X.48.1.26

Greenberg, J., Brinsfield, C. T. \& Edwards, M. S. (2007). Silence as deviant work behavior: The peril of words unspoken", in symposium presented at the annual meeting of the Society for Industrial and Organizational Psychology, 2007, New York, NY. 
Dunham, A. H., \& Burt, C. D. (2009). Mentoring and the Transfer of Organizational Memory within the Context of an Aging Workforce: Cultural Implications for Competitive Advantage. Cultural Implications of Knowledge Sharing, Management and Transfer: Identifying Competitive Advantage, IGI Global, Hershey, PA, 252-275.

Howell, K. E. \& Annansingh, F. (2013). Knowledge generation and sharing in UK universities: A tale of two cultures?", International Journal of Information Management, 33 (1), 32-39.

Hughes, T., Tapp, A. \& Hughes, R. (2008). Achieving effective academic/practitioner knowledge exchange in marketing, Journal of Marketing Management, 24, (1-2), 221-240. http://dx.doi.org/10.1362/026725708X274019

Husted, K. \& Michailova, S. (2002). "Diagnosing and fighting knowledge-sharing hostility", Organizational dynamics, 31 (1), 60-73. http://dx.doi.org/10.1016/S0090-2616(02)00072-4

Karanc1, A. N., Dirik, G. \& Yorulmaz, O. (2007). Reliability and Validity Studies of Turkish Translaon of Eysenck Personality Quesonnaire Revised-Abbreviated, Türk Psikiyatri Dergisi [Turkish Journal of Psychiatry], 18 (3), $1-7$.

Kasimoglu, M. \& Halici, A. (2002). Discrimination areas in higher education institutions in Turkey and a scale development study., International Journal of Educational Management, 16 (7), 333-338. http://dx.doi.org/10.1108/09513540210448095

Kidwell, J. J., Vander Linde, K. \& Johnson, S. L. (2000). Applying Corporate Knowledge Management Practices in Higher Education. Educause quarterly, 23 (4), 28-33.

King, W. R. (2008). "Knowledge Sharing”, in Jennex, M. (Ed.), Knowledge management: concepts, methodologies, tools and applications, IGI Publishing, 73-80. http://dx.doi.org/10.4018/978-1-59904-933-5.ch006

Konstantinou, E. \& Fincham, R. (2010). Not sharing but trading: Applying a Maussian exchange framework to knowledge management. Human Relations, 64 (6), 823-842. http://dx.doi.org/10.1177/0018726710388676

Land, F., Nolas, S. M., \& Amjad, U. (2005). Knowledge Management: The darker side of KM, Working Paper Seris, 13, 1-36.

Lee, H. L., So, K. C. \& Tang, C. S. (2000). The value of information sharing in a two-level supply chain" Management Science, 46 (5), 626-643. http://dx.doi.org/10.1287/mnsc.46.5.626.12047

Levey, A. B.\& Martin, I. (1981). "Personality and Conditioning". In Eysenck, H. J. (Ed.), The structure and measurement of intelligence, Springer, New York, 123-168. http://dx.doi.org/10.1007/978-3-642-67783-0_5

Lin, H. F. (2007). Effects of extrinsic and intrinsic motivation on employee knowledge sharing intentions. Journal of Information Science, 33 (2), 135-149. http://dx.doi.org/10.1177/0165551506068174

Lin, H. F. \& Lee, G. G. (2004). Perceptions of senior managers toward knowledge-sharing behaviour, Management Decision, 42 (1), 108-125. http://dx.doi.org/10.1108/00251740410510181

Lin, H. H \& Wang, Y. S. (2012). Investigating the Effect of University Students' Personality Traits on Knowledge Withholding Intention: A Multi-theory Perspective. International Journal of Information and Education Technology, 2 (4), 354-357. http://dx.doi.org/10.7763/IJIET.2012.V2.150

Matzler, K., Renzl, B., Müller, J., Herting, S. \& Mooradian, T. A. (2008). Personality traits and knowledge sharing, Journal of Economic Psychology, 29 (3), 301-313. http://dx.doi.org/10.1016/j.joep.2007.06.004

Mohayidin, M. G., Azirawani, M.N., Kamuriddin, N. \& Idawati, M. M. (2007). The application of knowledge management in enhancing the performance of Malaysian universities. Electronic journal of knowledge management, 5 (3), 301-312.

Mooradian, T., Renzl, B. \& Matzler, K. (2006). "Who trusts? Personality, trust and knowledge sharing. Management learning, 37 (4), 523-540. http://dx.doi.org/10.1177/1350507606073424

Muhenda, M. B., \& Lwanga, E. K. (2014). Knowledge Hoarding among Academic Staff in Higher Education Institutions in Uganda: Risk or Strategy? World Review of Business Research, 4 (2), 279-290.

Nawi, H. S. A., Shukor, N. S. A., Basaruddin, S., Rahim, N. M., Hassan, R. A. \& Jusoff, K. (2012). Determining the Existence of Knowledge Management Processes among Academicians", Journal of Knowledge Management Practice, 13 (2).

Peng, H. (2013). Why and when do people hide knowledge”, Journal of Knowledge Management, 17 (3), 398-415. 
Servin, G. \& De Brun, C. (2005). ABC of knowledge management: NHS National Library for Health: Specialist Library.

Srivastava, A., Bartol, K. M. \& Locke, E. A. (2006). Empowering leadership in management teams: Effects on knowledge sharing, efficacy, and performance", Academy of Management Journal, 49 (6), 1239-1251. http://dx.doi.org/10.5465/AMJ.2006.23478718

Takala, T. \& Urpilainen, J. (1999). Managerial work and lying: A conceptual framework and an explorative case study. Journal of Business Ethics, 20 (3), 181-195. http://dx.doi.org/10.1023/A:1006089527770

Tangaraja, G. \& Rasdi, R. M. (2013). Predictors of Knowledge Sharing Behaviour: A Proposed Model For The Malaysian Public Sector Managers. Graduate Research in Education, 238-248.

Tiwari T., Singh A.L. and Singh I.L. (2009), "The Short-Form Revised Eysenck Personality Questionnaire: A Hindi edition" (EPQRS-H), Ind Psychiatry, 18, 27-31. http://dx.doi.org/10.4103/0972-6748.57854

Tohidinia, Z. \& Mosakhani, M. (2010). Knowledge sharing behaviour and its predictors, Industrial Management \& Data Systems, 110 (4), 611-631. http://dx.doi.org/10.1108/02635571011039052

Wang, C. C. \& Yang, Y. J. (2007). Personality and intention to share knowledge: An empirical study of scientists in an R\&D laboratory. Social Behavior and Personality: an international journal, 35 (10), 1427-1436.

Watson, I. (2003). Applying knowledge management: Techniques for building corporate memories. Morgan Kaufmann, Amsterdam.

Webster, J., Brown, G., Zweig, D., Connelly, C. E., Brodt, S. \& Sitkin, S. (2008). Beyond knowledge sharing: Withholding knowledge at work, Research in personnel and human resources management, 27, 1-37. http://dx.doi.org/10.1016/S0742-7301(08)27001-5

Xenoudaki, C. \& Stafyla, A. (2012). Contextual Factors and Personality Traits in the Exhibition of Deceiving and Hiding-Related Behaviors of Employees, in Post Layoff Environments in Greece" in 9th International Conference on Enterprise Systems, Accounting and Logistics (9th ICESAL 2012), in Chania, Crete, Greece, 201, 369-389. 